\title{
DIÁLOGO DA NATUREZA E UM PIRATA: A ECOCRÍTICA POR UMA PERSPECTIVA DESCOLONIZADORA EM A VISÃO DAS PLANTAS DE DJAIMILIA PEREIRA DE ALMEIDA
}

\section{DIALOGUE BETWEEN NATURE AND A \\ PIRATE: ECOCRITICISM FOR A DECOLONIAL PERSPECTIVE IN DJAIMILIA PEREIRA DE ALMEIDA'S A VISÃO DAS PLANTAS}

Nicola Biasio ${ }^{1}$

\section{RESUMO}

O presente artigo propõe apresentar o romance $A$ visão das plantas, de Djaimilia Pereira de Almeida, através de uma chave de leitura ecocrítica e pós-colonial, a fim de destacar a relevância desse livro na produção literária da autora e no panorama da literatura da pós-memória afrodescendente. Em Portugal, a ecocrítica é uma disciplina que ainda não tem sido suficientemente utilizada como possibilidade metodológica de desconstrução das oposições binárias entre cultura/natureza e humano/não-humano que fundam o binómio colonizador/colonizado. A visão das plantas possibilita essa leitura ecocrítica de questões pós-coloniais, enfatizando em particular o tema da culpa. Para se inserir no grande debate da literatura, o romance conta uma história colonial visando descolonizar aquele mesmo passado que as segundas e terceiras gerações de afrodescendentes questionam no Portugal contemporâneo.

PALAVRAS-CHAVE: Djaimilia Pereira de Almeida. Ecocrítica. Pós-colonialismo. Pós-memória. 


\section{ABSTRACT}

This article proposes to read the novel $A$ visão das plantas by Djaimilia Pereira de Almeida through an ecocritical and postcolonial perspective, in order to highlight the relevance of this book in the author's literary production and in the overview of Afro-descendant post-memory literature. In Portugal, ecocriticism is a discipline that has not yet been sufficiently used as a methodological possibility for the deconstruction of the binary oppositions between culture/nature and human/non-human that create the colonizer/ colonized binomial. A visão das plantas enables this ecocritical reading of postcolonial issues, emphasizing in particular the theme of guilt. To insert itself in the great debate of literature, the novel tells a colonial story in order to decolonize that same past that the second and third generations of African descendants question in contemporary Portugal.

KEYWORDS: Djaimilia Pereira de Almeida. Ecocriticism. Post-colonialism. Post-memory.

\section{ERA UMA VEZ EM ÁFRICA}

Entre 21 e 30 de maio de 1824, Giacomo Leopardi escreveu um dos textos mais famosos das suas Operette morali: o "Dialogo della Natura e di un Islandese". Depois de ter viajado pelo mundo afora para fugir das amarguras ínsitas na vida humana, um Islandês chega à África equatorial, lugar onde encontra uma figura gigantesca que o narrador compara logo ao gigante Adamastor do canto V d'Os Lusíadas, de Camões ${ }^{3}$. Diversamente da personagem do poema épico, no texto de Leopardi é a personificação da Natureza que aparece, a qual revela ao Islandês, curioso em saber o porquê do sofrimento humano, o segredo do seu modus operandi.

NATUREZA: Por acaso - imaginaste que o mundo tenha sido feito por vossa causa? Pois é bom que saibas que nas minhas realizações, ordens e operações, com exceção de pouquíssimas, sempre tive e tenho a intenção inteiramente oposta à felicidade dos homens ou à desventura deles. Quando - vos ofendo de qualquer modo, ou por qualquer meio, - não percebo a não ser raríssimas vezes: do mesmo modo - não tomo conhecimento quando - vos distraio e vos agrado, e não como - credes, tais coisas ou ações faço para agradar-vos ou deleitar-vos. Finalmente, se me ocorresse extinguir toda a tua espécie, disso - não me aperceberia (LEOPARDI, 1992, p. 125).

A Natureza leopardiana apresenta-se como uma entidade a qual desconhece o poder da sua influência na vida dos seres humanos e que simplesmente flui em "perpétuo circuito de produção e destruição, ambas ligadas entre si de maneira que cada uma sirva continuamente à outra e à conservação do mundo" (LEOPARDI, 1992, p. 126). Uma Natureza "madrasta" que, segundo a crítica tradicional, marca a passagem de um pessimismo existencial para um pessimismo radical, materialista e cósmico no pensamento do autor italiano (BLASUCCI, 1985, p. 217). 
A viagem do Islandês no coração de África para entender o sentido da vida humana em relação ao progredir da natureza é comparável a uma outra viagem, a do Capitão Celestino, personagem que provém do livro Os pescadores, de Raul Brandão (1923), e que se torna protagonista do breve romance A visão das plantas de Djaimilia Pereira de Almeida, escritora que ganhou fama e notoriedade com Esse cabelo (2015) e Luanda, Lisboa, Paraíso (2018). A viagem de Celestino já não é mais uma viagem de ida ao "coração das trevas" do continente africano, mas de regresso a Portugal, depois de uma vida "misteriosa e feroz" (BRANDÃO apud ALMEIDA, 2019, p. 9). À espera dele, na casa na Foz do Douro, não há a personificação da Natureza, mas algo muito semelhante: um jardim paradisíaco que contrasta com a figura nefanda de Celestino, velho traficante de pessoas escravizadas.

A visão das plantas marca uma mudança significativa na poética da escritora. Margarida Calafate Ribeiro lembra que tanto Esse cabelo como Luanda, Lisboa, Paraíso são "narrativas ficcionais de lastro autobiográfico de identificação dos seus próprios sujeitos enquanto minorias de uma comunidade mais vasta” (2020, p. 293) e que, através do trabalho da pós-memória, contribuem para construir uma nova linha literária em Portugal - a da literatura "afropea" ou "afropolitana" -, que descreve e situa os filhos da segunda e terceira geração de migrantes das ex-colônias africanas que nasceram em Portugal não apenas como sujeitos diaspóricos (RIBEIRO, 2020, p. 294) ou "estranhos em permanência" (MATA, 2006, p. 285), mas como cidadãos portugueses que procuram um próprio espaço geopolítico em Portugal e na Europa através dos questionamentos artísticos que a literatura e as artes colocam.

Assim, os primeiros dois romances de Djaimilia Pereira de Almeida analisam as identidades hifenizadas em Portugal, herdeiras dos restos coloniais de um passado que ainda influencia o presente do país. Porém, em uma entrevista, a escritora afirma que "interessa-me afastar-me do meu próprio ponto de vista e virar-me para fora, para o ponto de vista dos outros e aproximar-me de outras figuras que não eu" (LUCAS, 2018, online). Desse modo, Djaimilia Pereira de Almeida sente a necessidade de se afastar dos primeiros livros de ficção autobiográfica para entrar em outro mundo literário, para poder participar da grande e antiga conversa da literatura, porque, de acordo com a escritora, "os livros preservam o sentido da discussão e mantêm entre si uma discussão própria, que nos ultrapassa, que se prolonga para lá de nós e para lá do momento que estamos a viver" (LUCAS, 2018, online).

Para se inserir nesse tipo de conversa que dura além do tempo em que o texto literário está inscrito, Djaimilia Pereira de Almeida volta a uma temporalidade que não lhe pertence diretamente, mas que influi na construção do Portugal de hoje: trata-se do passado remoto e, ao mesmo tempo, fantasmagórico do império português (sem, aliás, nunca o mencionar) personificado na personagem do Capitão Celestino, que regressa à casa para morrer em paz, "após uma vida cheia" (ALMEIDA, 2019, p. 11) de tráfico de seres humanos entre a África e o Brasil. Se em Esse cabelo e 
em Luanda, Lisboa, Paraíso vemos que "quando o império se desmoronou é que se cumpriu a sua quintessência messiânica da pluricontinentalidade e da multirracialidade" (MATA, 2006, p. 299) em Portugal, em A visão das plantas se volta a um momento de fundação do império português, baseado no tráfico de pessoas escravizadas no Atlântico Sul. Djaimilia Pereira de Almeida regressa ao passado e conta uma história colonial para descolonizar aquele mesmo passado. Entretanto, a descolonização daquele passado passa por uma metodologia "nunca de antes navegada" em Portugal: a da ecocrítica.

É Inocência Mata que, em qualidade de jurada no Prêmio Oceanos de 2020, aponta para A visão das plantas - que aliás ficou em segundo lugar - como "uma reflexão sobre a pós-humanidade, em que diferentes entendimentos de 'meio ambiente' são revelados e explorados. Mais do que perseguir o fim da vida de um homem cujo passado é muito obscuro, a narrativa questiona o lugar do humano na natureza." (2020, online). Trata-se, ainda segundo a professora, de "uma história em que representações da não-humanidade - as plantas, as flores, os frutos, os animais, os fenômenos atmosféricos - surgem como possibilidades redentoras da condição humana" (MATA, 2020, online). Partindo dessa reflexão, o presente artigo propõe ler o romance de Djaimilia Pereira de Almeida através de uma chave de leitura ecocrítica que, necessariamente, se cruza com uma perspectiva pós-colonial das memórias literárias residuais das segundas e terceiras gerações de afrodescendentes portugueses.

\section{ECOCRÍTICA, PÓS-COLONIALISMO E LITERATURA}

A ecocrítica - ou, em inglês, ecocriticism - é um novo ramo das ciências humanas que, a partir do começo deste século, começou a refletir com novas perspectivas sobre a clássica oposição binária cultura/natureza (ZAPF, 2010, p. 136). Por um lado, a ecocrítica nasce por uma exigência de abrir a crítica literária a uma perspectiva ecológica, através das diferentes disciplinas que estudam o funcionamento do meio ambiente; por outro, se origina a partir de uma urgência concreta que, perante as alterações climáticas e as crises ambientais, quer recuperar uma relação crítica entre texto e referente, entre dimensão ficcional e contexto real.

Nesse sentido, o conceito de cultural ecology é fundamental na economia do pensamento ecocrítico. A ecologia cultural é uma perspectiva paradigmática do conhecimento que funciona não apenas para as ciências naturais, mas também para os estudos culturais e que considera a esfera da cultura humana não como separada dos processos ecológicos e dos ciclos da energia natural, mas como parte interdependente daqueles mesmos processos e ciclos (ZAPF, 2010, p. 137). Igualmente aos processos naturais de produção, redução, destruição e consumação de energia, os ecosistemas culturais da arte e da literatura seguem os mesmos ciclos, envolvendo forças psíquicas e físicas internas a um sistema de auto-renovação paragonável a o da natureza. 
De acordo com Hubert Zapf (2010, p. 138), os seres humanos não são apenas "cultural beings", mas também seres instintivos, criando um elo incindível entre cultura e natureza. Segundo a perspectiva ecocrítica, a literatura e as outras formas culturais da imaginação se tornam um espaço fundamental de recuperação da riqueza, da diversidade, da pluralidade e da complexidade da relação entre homem e mundo natural, extirpadas pelos processos capitalistas e colonialistas atuais. Zapf escreve que

the mutual opening and symbolic reconnection of culture and nature, mind and body, human and nonhuman life in a holistic and yet radically pluralistic way seems to be one significant mode in which literature functions and in which literary knowledge is produced (2010, p. 139).

Deste modo, a literatura é descrita pela ecocrítica como um medium simbólico de uma forma particularmente poderosa de ecologia cultural, porque tem a capacidade de contra-atacar a interpretação e exploração econômica, política e pragmática da vida humana e de quebrar a visão monodimensional do mundo e do ser, abrindo-se para perspectivas marginalizadas, oprimidas e excluídas que desde sempre caracterizaram a alteridade no mundo natural e ecológico (ZAPF, 2010, p. 138).

A questão da alteridade e do "outro" no contexto ecocrítico é fortemente ligada à oposição binária humano/não-humano. Em Letteratura e ecologia, Niccolò Scaffai (2017) trabalha em direção de um compromisso entre paradigma holístico, que simplifica as complexidades da ecocrítica anulando a distinção entre humano e não-humano, e um outro paradigma separatista que, há séculos, coloca a humanidade como dominadora indiscutível da natureza. A proposta de Scaffai constrói um paradigma distintivo que transforma a distância entre o "eu" e o mundo em um recurso cognitivo e artístico que baseia a sua perspectiva da realidade e da literatura no efeito de estranhamento, que joga, nos textos literários, com uma inversão de papéis e olhares, e que desconstrói a visão antropocêntrica através de uma inversão de planos entre humano e animal, entre natural e artificial, sem, contudo, propor hierarquias (SCAFFAI, 2017, p. 17). A anulação de hierarquias entre o humano e o não-humano se insere de forma muito interessante na política desconstrutivista já inaugurada pelos estudos pós-coloniais. Nesse sentido, a ecocrítica compartilha com o pós-colonialismo a necessidade de superar a perspectiva euro e américo-cêntrica e a interpretação orientalista da natureza (SCAFFAI, 2017, p. 70).

Para entender o elo entre ecocrítica e pós-colonialismo, temos que voltar atrás para o momento de fundação desse último movimento. Em Culture and Imperialism, Edward Said descreve o imperialismo como "an act of geographical violence" através do qual "every space in the world is explored, charted, and finally brought under control" (1993, p. 225). Por muito tempo, o colonialismo legitimou seu estatuto político através de narrativas comemorativas, enfatizando viagens heróicas de descoberta, exploração e apropriação em territórios terrestres e oceânicos considerados "vazios" - e 
portanto legitimamente colonizáveis -, justificando a administração e controles externos. Como resposta a essa exploração de longo prazo, a recuperação da soberania e do controle direto da terra e dos recursos naturais por parte das populações nativas tem sido uma questão vital dos movimentos de descolonização pelo mundo afora. Como consequência, unir a ecocrítica aos estudos pós-coloniais se torna uma forma poderosa tanto para analisar os efeitos do imperialismo e da globalização nos diferentes ecossistemas que foram colonizados pelo Ocidente, quanto para ver como os dois paradigmas desconstrutivistas operam de forma semelhante na literatura, a fim de contribuir para uma revisão histórica, cultural e política do binômio colonizador/ colonizado através de uma chave de leitura ecológica.

Como a categoria da "raça", a "natureza" também é uma construção social que depende da sua separação da "cultura" e do "ser humano" (CARRIGAN, 2015, p. 82). Através da associação que une a "natureza" ao colonizado e a "cultura" ao colonizador, o colonialismo cria uma rede de relações assimétricas onde a inferiorização do "outro" da colonização se manifesta também na exploração geográfica, natural e ambiental da terra dos "outros". A isto se junta a oposição humano/não-humano, que, agora, não reflete apenas o binómio colonizador/colonizado, mas também o posicionamento do colonizador em relação à terra "vazia" que, igualmente aos povos nativos, está inscrita no reino "animal" ao qual não se reconhece um estatuto paritário ao mundo "humano". Nesse sentido, a ecocrítica aplicada ao contexto pós-colonial se abre para outro ramo de extremo interesse: a pós-humanidade, disciplina que tenta revisionar as relações de poder entre o humano e o inorgânico, o natural e o artificial, o homem e o animal e, por último, entre os seres humanos e o meio ambiente.

Como lembra Louise Westling, a pós-humanidade no contexto ecocrítico revela "the human place within the ecosystem by interrogating or erasing the boundary that has been assumed to set our species apart from the rest of the living community" (2006, p. 30). Levando em conta todos esses aspectos, a análise ecocrítica da literatura colonial revela "how literary texts represent power relations as environmentally embedded" (CARRIGAN, 2015, p. 82). O que os escritores pós-coloniais, em uma vertente ecocrítica, tentam fazer com suas obras é justamente desconstruir essas relações de poder ambientalmente incorporadas nas narrativas coloniais. Por isso, o romance pós-colonial, lido através de uma perspectiva ecocrítica, representa uma nova sensibilidade em representar a justiça social como estreitamente interligada à justiça ambiental, ambas vítimas das relações opressivas do poder colonial. A pergunta comum à qual esse gênero literário tenta responder é: existe alguma forma de desconstruir a relação entre colonizador e colonizado através de uma perspectiva ecológica que reconfigure as oposições de natureza/cultura e de humano/não-humano, oposições que estabelecem as relações assimétricas ínsitas no binómio colonizador/colonizado fundador da mitologia colonial? (HUGGAN; TIFFIN, 2015, p. 2). Com A visão das plantas, Djaimilia Pereira de Almeida tenta dar uma resposta, ou talvez, melhor, colocar perguntas acerca dessas questões no contextos das memórias pós-coloniais e residuais no Portugal das segundas e terceiras gerações de sujeitos diaspóricos. 
Entre os anos 1750 e 1850, as viagens negreiras para o Brasil atingiram seu auge. Em 1923, Raul Brandão descreve, entre as diferentes personagens de Os pescadores, a figura do Capitão Celestino que "tendo começado a vida como pirata a acabou como um santo, cultivando com esmero um quintal de que ainda hoje me não lembro sem inveja" (BRANDÃO apud ALMEIDA, 2019, p. 9). Em 2019, Djaimilia retoma essa frase que descreve a vida antitética do homem para imaginar um enredo aparentemente simples: o pirata cuidando do seu jardim, o fim de uma vida, as marcas que ficaram dela e o enigma acerca da justiça. Como escreve Gustavo Rubim (2020, online), é a memória do império português e a reflexão sobre suas contradições e violências que continuam em jogo na escrita de Djaimilia Pereira de Almeida e na atual discussão da pós-colonialidade em Portugal.

A peculiaridade de $A$ visão das plantas está no ponto de vista da narração. A população da aldeia murmura histórias acerca do passado sangrento do pirata: histórias de degolações, esquartejamentos, espancamentos, furtos, feitiços maléficos e devoção ao Diabo. As cenas mais aterradoras são o episódio da mortandade coletiva por sufocamento de um grupo de escravizados trancados no porão do navio negreiro depois de Celestino ter jogado cal sobre eles (ALMEIDA, 2019, p. 38) e a história do abandono, no meio do mato, de uma menina holandesa, atada a uma árvore e vendada (ALMEIDA, 2019 , p. 25). Enquanto essas histórias pairam no ar, o padre da aldeia continua repetindo a mesma frase ao longo do romance: "Não se quer confessar, capitão? Nunca é tarde" (ALMEIDA, 2019, p. 66). A resposta a todos esses crimes é um dúplice silêncio: o de Celestino, o qual nunca confirmará ou negará as atrocidades narradas, e o das plantas do seu jardim, as quais "tanto lhes fazia serem cuidadas por um assassino, se eram sujas as mãos que as amparavam ou o que viera antes do amor que ele lhes dedicava" (ALMEIDA, 2019, p. 37).É justamente através desse "olhar sem julgamento" (ALMEIDA, 2019 , p. 37) das plantas que a história do fim da vida de Celestino é narrada, e isso gera a ambiguidade de fundo do romance e questiona, sem dar uma resposta definitiva, o conceito de justiça no debate literário pós-colonial. Como é que um homem que cometeu tantos crimes não se julgou, nem se sentiu arrependido? Como é possível que alguém que trabalhou a vida toda com a morte, agora consegue dar a vida a um jardim de tamanha beleza? $\mathrm{O}$ livro tenta ver a vida de um homem a partir dessa visão "sem julgamento" sobre um passado moral e humanamente depravado. Por isso, Djaimilia opta por utilizar a visão orgânica das plantas como metodologia narrativa, as quais apenas se interessam de beber e existir, ignorando tanto o passado do pirata como o amor e o zelo que Celestino coloca cuidado do jardim que, ele pensa, o ama de volta. Nada disso:

Por maiores que fossem os cuidados do jardineiro, às plantas tanto lhes fazia viver ou morrer. Tanto lhes dava que ele se finasse no sono ou voltasse a quintal todos os dias. Tanto lhes dava que tivesse encontrado nelas uma razão de viver ou as 
amasse. Se lhes faltasse a rega, murchariam. Não seria por mal, não o levavam a mal. Nada esperavam dele (ALMEIDA, 2019, p. 37).

O julgamento da vida do Capitão é suspendido pela visão das plantas, mas a dualidade entre crime e redenção persiste no romance, criando no enredo uma complicada rede de relações assimétricas nas quais não é claro onde está o controle do poder entre o jardim e o jardineiro, entre a vítima e o opressor. O que é interessante no romance de Djaimilia é ver como o uso do mundo da natureza permite atuar a desconstrução das assimetrias, invertendo os papéis de poder naquelas mesmas relações. Por isso, a atenção da autora se desloca da moral para o cuidado na construção do jardim e do mundo natural em volta a Celestino, lugar onde se concretiza a inversão (e a ambiguidade) dos poderes.

Em Luanda, Lisboa, Paraíso havia um doente (Aquiles) e um cuidador (Cartola), embora a certa altura, quando os dois se mudam para o bairro chamado Paraíso, não resulte bem claro quem cuida de quem. Em A visão das plantas também não é claro quem está dominando e quem está sendo dominado. Inicialmente, Celestino se apresenta como jardineiro que corta, monda, poda e constrange o crescimento do jardim selvagem e abandonado há anos para o transformar em um éden paradisíaco sem igual, em perfeita consonância com a vontade colonialista de domínio que legitimiza a exploração da natureza e dos “outros” que nela vivem. O jardineiro representa no romance uma figura de dominação e de exercício de poder. Em contrapatrida, na medida em que Celestino fica mais velho, cego e próximo à morte, a situação muda drasticamente: é a vida de Celestino que começa a depender inteiramente das plantas do jardim, as quais se tornam sua única razão para sobreviver a uma vida cheia de culpas do passado que assombram os dias e as noites do pirata. A atuação da inversão das relações assimétricas acontece quando o narrador revela a verdadeira natureza do jardim de Celestino:

Se alguém pensasse que cultivava as flores do seu caixão, soubesse que as rosas, os cravos, as surpresas suas de cada dia, cada uma das ameixas que quase lhe sabiam a ananás dos Açores eram no futuro do capitão os números, as caras, as almas de quantos, mortos pelas suas mãos ou delas testemunhas, lhe ofereciam agora o seu silêncio eterno, ali plantados, carecidos da água do seu regador, do alimento do seu poço (ALMEIDA, 2019, p. 45).

Embaixo da terra do jardim de Celestino, atado às raízes das plantas, há um porão de almas mortas pelas mãos do pirata; as mesmas mãos que, agora, as ressuscitam sob a forma de plantas, as quais viram a única razão de vida de Celestino. Através de uma reviravolta repentina, as antigas vítimas de Celestino se tornam as donas do velho pirata e escravizam a sua vida pelo simples fato de que o jardim passa a dar sentido à vida dele. 
Estava cativo do viço delas, escravo do cuidado que lhes punha e do amor que the ganhara, que lhes ganhara a elas. Supremo castigo: deixara-se escravizar, ao julgar erguer com as suas mãos um pequeno mundo, tesouro cuja destruição temia agora mais do que pela sua vida, que nada ameaçava. Se o seu corpo fora um navio no mar, a desafiar as marés e as correntes, o que o sustinha agora era a vida que, sem querer, gerara (ALMEIDA, 2019, p. 71).

É assim que o narrador diz, no final do livro, quando Celestino já está naufragando no mar do esquecimento e da loucura, que "não era mais ele que tomava conta das flores, mas elas que tomavam conta dele. [...] Quase fora deste mundo, o jardineiro deixara de ser o jardim, porque o jardim se tornara jardineiro do jardineiro" (ALMEIDA, 2019, p. 86). A desconstrução da figura do opressor atinge, com essas palavras, seu auge: Celestino não consegue mais viver sem suas plantas, que na verdade são a reencarnação das vítimas feitas na vida pelas suas mãos atrozes. Não é por acaso que Jeferson Tenório, em recente resenha sobre o livro, utiliza a expressão "narrativa das mãos" para definir o livro de Djaimilia, mãos que nos conduzem "ao universo da possibilidade das injustiças" e que colocam a seguinte pergunta: "o que as mãos são capazes de fazer e ainda assim continuar impunes?” (TENÓRIO, 2021, online).

Em A visão das plantas, o tema da culpa se torna o tema da indiferença. Celestino não chega a se julgar e confessar em vida, embora tente expiar seu passado cultivando as flores e as plantas dos seu jardim - lugar de aparente proteção, onde não há espaço para julgamentos -, como se o corsário pudesse sufocar embaixo da terra e sob as raízes das plantas os crimes cometidos no Atlântico. A violência colonial está sempre presente no romance, mas não como memória traumática que assombra o capitão. Pelo contrário, trata-se quase de um prazer sádico que goza das brutalidades cometidas que ele mesmo tenta recriar no seu jardim: "O sangue, da lascívia e da volúpia, a morte, em todas as suas declinações lúgubres, tudo tinha no quintal o seu duplo, na forma de cada planta, que, com mãos delicadas de mulher, tratava como pessoas" (ALMEIDA, 2019, p. 44).

Através da inversão de papéis de poder entre Celestino e o jardim, o Império português que o pirata ajudou a construir com o tráfico de seres humanos se reconfigura no quintal como um império de plantas, flores, árvores e insetos, que mostra a Celestino a mesma indiferença que ele nutria ao cometer atrocidades contra suas vítimas. Para não morrer, Celestino precisa do amor do jardim que, pelo contrário, o ignora. Dado que a vida do homem depende totalmente do jardim, o pirata se torna vítima da mesma violência que ele cometeu contra os escravizados que pediam clemência para as suas vidas. Conforme a teoria crítica elaborada por Blasucci (1985, p. 217) na interpretação da Natureza leopardiana, o jardim do Capitão Celestino é "madrasto", no sentido de que não se interessa por quem o cultiva ou por quem o ama. Celestino não é nada mais do que uma sombra no quintal e que faz parte daquele perpétuo circuito de produção e destruição do mundo da natureza orgânica. 
Djaimilia Pereira de Almeida configura o jardim do Capitão Celestino como Umwelt, conceito introduzido pelos fundadores do pensamento ecológico da metade do século XIX, categoria com a qual se pode narrar o meio ambiente através de uma visão ecossistêmica do mundo, em que os habitantes humanos e não-humanos são contemporaneamente sujeitos e objetos da narração literária. O conceito de Umwelt permite abraçar um paradigma distintivo, capaz de conjugar perspectivas diferentes tanto no interior do texto literário, através da técnica do estranhamento, como no interior da própria análise literária crítica, que se torna, assim, o vetor de uma reflexão capaz de superar um olhar antropocêntrico - ou egocêntrico - para uma leitura multifocal do mundo. É isso mesmo que acontece em A visão das plantas. A narração do fim da vida de Celestino é filtrada pela visão das plantas, as quais são totalmente indiferentes perante à próxima morte do pirata. A técnica de estranhamento consiste em "contar" o que as plantas "pensam" de Celestino ao longo da narração. Asserções como "as plantas viam o jardineiro como as plantas veem" (ALMEIDA, 2019, p. 37) e "se lhes fazemos perguntas, as árvores, os ramos, as folhas respondem" (ALMEIDA, 2019, p. 47) instauram um mútuo diálogo mudo entre Celestino e o jardim, acerca da questão da justiça, do castigo, da indiferença e da morte. O resultado é de uma ambiguidade sem pares.Na vida, Celestino foi um monstro, apesar do seu estatuto ontológico de "humano". Na velhice e próximo à morte, a personalidade do pirata revela uma natureza híbrida e contraditória entre a violência da vida passada e o amor incondicional pelo seu jardim (ou seja, pelas suas vítimas). É nessa última fase da vida, em que Celestino parece se tornar "humano", que começa a desconstrução ontológica da personagem e que o aproxima à categoria do não-humano representada pelas plantas do seu quintal. Apesar das relações assimétricas, Celestino e as plantas manifestam o mesmo sentimento de indiferença para com os outros seres viventes, chegando a compartilhar o mesmo estatuto ontológico: "Elas e o seu amigo eram seiva da mesma seiva, da mesma carne sem dó nem piedade. Atrás das costelas, no lugar do coração, o corsário tinha uma planta" (ALMEIDA, 2019, p. 39). O corpo de Celestino passa por uma metamorfose orgânica que anula a distinção humano/não-humano, porque "os caules, os ramos, as flores, os frutos eram o seu cabelo, os braços, as pernas, os seus únicos pensamentos, a sua razão de viver" (ALMEIDA, 2019, p. 71), até quebrar qualquer delineação ontológica, dado que "o esfumar do homem esfumava o mundo à sua volta” (ALMEIDA, 2019, p. 82). Nessa perspectiva ecocrítica, o romance de Djaimilia não questiona apenas quem detém o poder, mas também quem pode ser ainda considerado "humano" dentro do quintal do velho pirata.

\section{AS VOZES DO SILÊNCIO E OS ANJOS QUE NÃO GUARDAM RANCOR}

Como explicamos ao longo do artigo, em $A$ visão das plantas o tema da culpa passa em segundo lugar na economia do romance. Ou melhor, o enfoque sobre a culpa não é mais funcional em relação ao enredo ecocrítico promovido no livro. A suspensão do juízo sobre o passado (e o presente) de 
Celestino é a mesma suspensão crítica oferecida pela visão das plantas do seu jardim. O que resulta totalmente inovador acerca do tema da culpa ligada ao passado colonial nesse livro é a tentativa de colocar perguntas para entender, mais do que para julgar aquele passado. Nessa perspectiva, a ecocrítica é vital para compreender a morte impune de Celestino, o qual "acabou seus dias, sem uma dúvida na consciência tranquila” (ALMEIDA, 2019, p. 88).

Antes de morrer, Celestino é visitado em particular por dois fantasmas das relativas vítimas feitas em vida, o da menina holandesa dos olhos vendados (que ele tinha abandonado no mato) e o de uma velha escrava negra (sufocada no porão do navio negreiro). Por paradoxal que pareça, essas duas almas também não o julgam, acompanhando-o até o final da sua vida como dois "anjos sem rancor que o guardavam" (ALMEIDA, 2019, p. 81). O romance é, então, uma importante reflexão sobre a possibilidade, no contextos das questões pós-coloniais, de ser acolhido e amparado por aquilo e por quem que foi calado, explorado, dominado ou morto na vida, como foi no caso de Celestino em relação às suas vítimas: nem as plantas, nem os fantasmas o assombram ou castigam; simplesmente o acompanham em silêncio até a morte e o esquecimento.

Em última instância, A visão das plantas é um livro sobre o silêncio e a tentativa de dar voz àquele silêncio. Em Le Visible et l'invisible ${ }^{4}$, o filósofo francês Maurice Merleau-Ponty formula o conceito de "vozes do silêncio", que nasce da reflexão de que o mundo natural nos fala através de uma língua que não entendemos a nível cognitivo, mas sim a nível da experiência sensorial (1973, p. 127). Merleau-Ponty aponta para uma necessidade de despertar a voz do mundo que nos rodeia, o que exige ouvir as vozes "outras" de que nos esquecemos, vozes que surgem naquilo que anteriormente poderíamos ter presumido serem silêncios (1973, p. 155). Dando a voz às plantas e aos fantasmas, A visão das plantas nos convida a ouvir o silêncio que a dominação e a violência do mundo colonial produziu. O silêncio é só aparente; como as vítimas de Celestino tiveram uma voz própria que o Império português desde sempre silenciou, da mesma forma as plantas do quintal do pirata falam silenciosamente sobre aquele passado, murmurando no vento entre os choupos da casa do pirata. Contudo, essa conversa entre flores, plantas, ventos, animais, insetos e fantasmas é uma fala sem julgamento, sem imputação de culpa, sem castigos. É uma conversa "orgânica" sobre o agora e a sobrevivência no presente que flui junto ao progredir da natureza.

No panorama literário da pós-memória afrodescendente em Portugal, A visão das plantas de Djaimilia Pereira de Almeida desenvolve um papel inovador e de grande mérito para refletir sobre o passado colonial e suas heranças no presente do país. Através da visão inusual das plantas, o verdadeiro intento do livro é o de suspender o juízo sobre o passado para nos convidar a pôr atenção àquele diálogo mútuo e silencioso entre homem e natureza, entre dominador e dominado, entre opressor e vítima, em vista de uma possível política que não seja de acusação, mas sim de conciliação no futuro de Portugal. 


\section{REFERÊNCIAS}

ALMEIDA, Djaimilia Pereira de. A visão das plantas. Lisboa: Relógio D’Água, 2019.

BLASUCCI, Luigi. Leopardi e i segnali dell'infinito. Bologna: Il Mulino, 1985. BRANDÃO, Raul. Os pescadores. Lisboa: Aillaud e Bertrand, 1923.

CAMÕES, Luís Vaz de. Os Lusíadas. Perugia: Edizioni dell’Urogallo, 2011.

CARRIGAN, Anthony. Nature, Ecocriticism, and the Postcolonial Novel. In: QUAYSON, Ato (org.). The Cambridge Companion to the Postcolonial Novel. Cambridge: Cambridge University Press, 2015, p. 81-98.

HUGGAN, Graham; TIFFIN, Helen. Postcolonial Ecocriticism: Literature, Animals, Environment. New York: Routledge, 2015.

LEOPARDI, Giacomo. Opúsculos Morais. São Paulo: Editora Hucitec, 1992.

LUCAS, Isabel. Djaimilia Pereira de Almeida: não é só raça, nem só género, é querer participar na grande conversa da literatura. Público, Lisboa, 20 dez. 2018. Disponível em: https://www.publico.pt/2018/12/20/culturaipsilon/ noticia/djaimilia-1854988. Acesso em: 25 abr. 2021.

MATA, Inocência. Conheça os livros vencedores do Oceanos 2020. Itaú Cultural, São Paulo, 18 dez. 2020. Disponível em: https://www.itaucultural. org.br/secoes/noticias/conheca-livros-vencedores-oceanos-2020. Acesso em: 24 abr. 2021.

. Estranhos em permanência: a negociação da identidade portuguesa na pós-colonialidade. In: SANCHES, Manuela Ribeiro (org.). "Portugal não é um país pequeno”: contar o 'império’ na pós-colonialidade. Lisboa: Livros Cotovias, 2006, p. 285-315.

MERLEAU-PONTY, Maurice. The Visible and the Invisible. Evanston: Northwestern University, 1973.

RIBEIRO, Margarida Calafate. Viagens na Minha Terra de "outros" ocidentais. In: RIBEIRO, Margarida Calafate; ROTHWELL, Phillip (orgs.). Heranças pós-coloniais nas literaturas de língua portuguesa. Porto: Edições Afrontamento, 2020, p. 291-307

RUBIM, Gustavo. Pirataria e jardinagem: É a memória do império português que continua em jogo na escrita de Djaimilia. Público, Lisboa, 2 mar. 2020. Disponível em: https:/www.publico.pt/2020/03/02/culturaipsilon/noticia/ pirataria-jardinagem-1905528. Acesso em: 24 abr. 2021.

SAID, Edward W. Culture and Imperialism. New York: Vintage Books, 1993.

SCAFFAI, Niccolò. Letteratura e ecologia: Forme e temi di una relazione narrativa. Roma: Carocci, 2017. 
TENÓRIO, Jeferson. A confissão do carrasco: Novo romance de ganhadora do Prêmio Oceanos revela a brutalidade e a delicadeza de um ex-capitão de navio negreiro. Quatro cinco um, São Paulo, 1 mai. 2021. Disponível em: https://www.quatrocincoum.com.br/br/resenhas/literatura/a-confissao-do-carrasco. Acesso em: 12 mai. 2021.

WESTLING, Louise. Literature, the environment, and the question of the posthuman. In: GERSDORF, Catrin; MAYER, Sylvia (orgs.). Nature in Literary and Cultural Studies: Transatlantic Conversations on Ecocriticism. Amsterdam: Rodopi, 2006, p. 25-47.

ZAPF, Hubert. Ecocriticism, Cultural Ecology, and Literary Studies.Ecozon@: European Journal of Literature, Culture and Environment, Universidad de Alcalá, v. 1, n. 1, p. 136-147, abril 2010.

Recebido para avaliação em 27/05/2021

Aprovado para publicação em 02/06/2021

\section{NOTAS}

1 Mestre em Literaturas Comparadas e doutorando em Women's and Gender Studies pela Universidade de Bolonha. Estuda as literaturas europeias afrodescendentes de autoria feminina e queer. Trabalha e colabora com a Universidade de Bolonha e o Centro Camões I.P. de Lisboa em qualidade tutor didático de cursos avançados na área dos estudos literários portugueses, brasileiros e pós-coloniais.

2 A tradução portuguesa da obra de Leopardi chega no Brasil em 1992, publicada pela Hucitec editora em colaboração com o Instituto Italiano de Cultura de São Paulo e o Instituto Ítalo-Brasileiro. A tradutora Vilma De Katinskyi Barreto de Sousa escolhe como título Opúsculos Morais.

3 É interessante ver a associação que Leopardi faz entre as viagens no continente africano e imaginário literário, resultando na citação direta do poema épico de Camões, o qual celebra as gestas das conquistas lusitanas e ao mesmo tempo canta as futuras derrotas do império português. O gigante Adamastor, representante simbólico do Cabo da Boa Esperança e guardião dos mares australes, é descrito com essas palavras: "Não acabava, quando uma figura / Se nos mostra no ar, robusta e válida, / De disforme e grandíssima estatura, / O rosto carregado, a barba esquálida, / Os olhos encovados, e a postura / Medonha e má, e a cor terrena e pálida, / Cheios de terra e crespos os cabelos, / A boca negra, os dentes amarelos" (CAMÕES, 2011, p. 135).

4 Para esse artigo, utilizamos a tradução inglesa do livro de Merlaeu-Ponty. 